This item was submitted to Loughborough's Research Repository by the author.

Items in Figshare are protected by copyright, with all rights reserved, unless otherwise indicated.

\title{
Not all roads lead to London: insularity, disconnection and the challenge to 'regional' creative industries policy
}

PLEASE CITE THE PUBLISHED VERSION

https://doi.org/10.1080/00343404.2020.1738012

PUBLISHER

Taylor \& Francis (Routledge)

VERSION

AM (Accepted Manuscript)

PUBLISHER STATEMENT

This is an Accepted Manuscript of an article published by Taylor \& Francis in Regional Studies on 6 April 2020, available online: http://www.tandfonline.com/10.1080/00343404.2020.1738012.

\section{LICENCE}

CC BY-NC-ND 4.0

\section{REPOSITORY RECORD}

Watson, Allan. 2020. "Not All Roads Lead to London: Insularity, Disconnection and the Challenge to 'regional' Creative Industries Policy". Loughborough University. https://hdl.handle.net/2134/11917923.v1. 
Not all roads lead to London: Insularity, disconnection and the challenge to 'regional' creative industries policy

\author{
Allan Watson \\ Geography and Environment, School of Social Sciences and Humanities, Loughborough \\ University, Loughborough, Leicestershire, LE11 3TU \\ A.Watson3@1boro.ac.uk
}




\title{
Not all roads lead to London: Insularity, disconnection and the challenge to 'regional' creative industries policy
}

\begin{abstract}
The notion of 'regional' economic growth through the creative industries is rendered problematic by the socio-geographical complexities that characterise them. Addressing an important conceptual and empirical deficit in our understanding of the creative industries at and beyond the regional level, this paper develops a novel and detailed examination of the music economy in north west England. Uncovering a significant disconnection with the mainstream industry in London - an obligatory point of symbolic validation and passage to wider markets - the paper argues that policy is required to support professionals in developing socio-spatial networking strategies to cope with their disconnected status.
\end{abstract}

\section{Key words}

Region, creative economy, creative industries policy, networks, clusters, music industry 


\section{Introduction}

It is two decades since creative industries emerged as a key pillar of economic development in the UK based around the anticipated national, regional and local socioeconomic benefits from a growing cultural and creative economy (Department of Culture, Media and Sports [DCMS], 2000, 2001). Despite the disappearance of England's Regional Development Agencies in 2012, policy discussions regarding the spatial rebalancing of the UK economy (see Martin, 2015; Martin et al., 2016) and regional growth strategies such as the 'Northern Powerhouse' (see Haughton et al., 2016; Lee, 2017; Parr, 2017) have retained a strong emphasis on the potential for clusters of creative industries within major cities to foster economic growth across the regions of the UK. The 2018 Creative Industries Sector Deal, a central part of the UK Government's Industrial Strategy, reaffirms how creative industries growth at the regional scale is firmly on the political agenda, and reveals a desire to develop "more world-class creative industries clusters to narrow the gap between London, the South East and other regions" (HM Government, 2018; 14).

Significant critiques have been levelled at policies that link urban and regional economic growth with creativity and the cultural creative industries. These include the narrow vision of creativity invoked in policy agendas, and the elision of cultural policy and economic development which "inappropriately over-economizes the arts and culture to the potential detriment of intelligent regional policy making" (Taylor, 2006; 4). More fundamentally, the notion of 'regional' economic growth through the cultural and creative industries is rendered problematic because it fails to fully understand its object of study. As Watson and Taylor (2014; 2430) argue, the "inability, unwillingness, and failure within cultural policy-making circles to understand the complex dimensions of cultural production has been a major reason for ineffective policy and misguided policy instruments". Indeed, for Pratt (2009), it is 
debatable whether a deep understanding of the creative/cultural industries has been achieved. As Pratt suggests, developing such an understanding carries a heavy burden of information and insight, yet despite the upsurge of analyses into the cultural and creative sector, the evidence base is "still broadly inadequate for the burden placed upon it by an ever more enthusiastic policy and political communities" $(2010 ; 181)$. Given there remains an inadequate evidence base to properly inform policy, there is a need therefore not to think about the creative economy in convenient theoretical and policy constructs, but rather in empirical terms (Granger and Hamilton, 2010). One particular issue lies in the fact that while much research on creative industries provides detailed case studies of specific cities or areas, both the geographical dimension and scale tend to be considered a-critically and, in particular, the regional or 'meso-level' has received rather scant attention (Chapain and Communian, 2010). For Markusen $(2010 ; 815)$ however, the strength of academic work on cultural industries lies not in the mapping of cultural industry concentrations, but rather in "case studies that reveal how these industries work within and across regional economies", while for Granger and Hamilton (2010), for regions to maximise the potential of the creative economy, more needs to be known about the role geography plays in creative processes.

Drawing on a detailed case study of the music economy in north west England, this paper begins the task of addressing the serious conceptual and empirical deficit in our understanding of the operation of the creative industries at and beyond the regional level. Through in-depth qualitative interviews with key actors regarding their local, region and extra-regional socio-spatial relations, the paper provides a rich account of the functioning of the musical economy in, through and beyond the region. The findings of the paper make an important conceptual and empirical contribution to the extant literature on regional creative economies, highlighting the importance of rich, industry-specific qualitative research. More 
specifically, the paper reveals not only the dynamics of the socio-spatial relations that underpin work in the musical economy, but crucially adds nuance to such accounts by revealing how insularity and disconnection can provide significant barriers in the creative economy. In this case, findings demonstrate that a disconnection exists between actors in the north west and the hub of the mainstream music industry in London, an obligatory point of symbolic validation and passage point to wider markets. Yet, while noting the potentially negative impact of the disconnection on the health and vibrancy of a regional creative economy, it also challenges cluster-based and London-centric policy narratives by revealing the complex socio-spatial strategies that local creative actors develop to cope with their disconnected status. Recognising the value of these strategies, the paper argues for an alternative and more inclusive creative economy policy that seeks to support professionals in developing multi-scalar links across a multi-locational milieu of regional cities.

\section{The creative economy, the region and the empirical deficit}

Culture continues to sit firmly at the heart of policies for local and regional economic development in the UK. Most recently, this has been evidenced through the Creative Industries Sector Deal of the UK Industrial Strategy, a £150m investment designed to boost the UK's creative industries (HM Government, 2018). Yet, as the Sector Deal report highlights, London accounts for $32 \%$ of creative industries employment in the UK, which rises to $48 \%$ taking the South East region more widely. In comparison, and despite the rhetoric in the Sector Deal report around the national spread of creative industries as narrowing the gap between the South East of England and the rest of the UK, the highest regional employment share outside the South East is $8 \%$, with the North West region accounting for just $7 \%$. One example of an attempt at 'rebalancing' given in the report is the MediaCityUK development in Salford, Manchester, and the relocation of 2,500 jobs by the 
BBC. This is celebrated in the report as an example of industry and central and local governments working together. Yet, the development could also be criticised as being based around unrealistically "bold economic-geographical claims" (Christophers, 2008) and as being little more than "a symbolic demonstration of the Corporation's commitment to regionalism" (Noonan, 2012; 375)

The problematic nature of employment measures for capturing the scope and value of work in a regional cultural economy not withstanding (Markusen 2010), these figures suggest that the UK's creative economy is highly unevenly distributed in geographical terms despite two decades of policy development aimed at driving economic growth across the UK's regions. The relative failure of successive rounds of policies to drive creative industries growth outside of the South East, whilst symptomatic of the economic disparities that exist both between regions and intra-regionally in the UK (Oakley, 2006), is also arguably in significant part due ineffective policy resulting from the inability or unwillingness within cultural policy-making circles to understand the complex dimensions of cultural production (Watson and Taylor, 2014). As Pratt (2010) has identified, an understanding of the local contexts and complexities of cultural production must be central to policy making given that "the same policies produce different effects and impacts under various institutional and social, cultural and economic contextual situations" $(2010 ; 14)$. One of the most significant problems in this regard has been the narrow focus on urban clusters as the key drivers of regional economic growth (see for example Florida et al., 2017), with what are considered to be particularly vibrant clusters of creative activity typically identified through some form of creative industries 'mapping' exercise, a strategy which began with the DCMS in 1998 and 2001 (see Cunningham and Higgs, 2008). This is highly problematic from a policy perspective, for two linked reasons; first it does not provide a substantive empirical data on 
the cities in which policy makers will implement their policies; and second it reflects that fact that the theories that influence these policies are often best understood as "theoretical generalizations of empirical knowledge derived from global cities and metropolises" (van Heur, 2010; 189) which introduce particular (metropolitan) geographical biases into policy.

Such an understanding of creativity - that is to say, as being strongly territorially articulated in large cities - is underpinned by a significant body of literature examining clusters of economic activity in leading cities. Building on the seminal work of Michael E. Porter (1998), economic-geographical literature on clustering has continued to place a strong emphasis on co-location, local 'buzz' (Storper and Venables, 2004), and internal dynamics of competition, cooperation and trust. The emphasis of the importance of place-based knowledge dynamics over more mobile dynamics has been a significant feature of the literature concerned with innovation in the creative industries, more so than in other sectors, due to the centrality of symbolic knowledge to these industries. Martin and Moodysson (2011), for example, in their examination of the media industry in Sweden find that firms are connected to each other in dense networks, with knowledge flows "very much locally configured" and occurring above all within regional boundaries $(2011 ; 1200)$. Such a 'territorial advantage' perspective undoubtedly offers much to our understanding of the dynamics of localised creative economies. However, focusing solely on the relations within a limited geographical locus (e.g. a cluster, or region) as the only ones that add value to local production offers only a partial and limited perspective. While a cluster approach may be convenient for policy makers due to the focus on a contained geographical concentration of actors, it is now well recognised that activities crucial to that cluster can be often be based well outside it (Chapain and Comunian, 2010; Trippl et al. 2015). Yet, despite this, non-local connections have predominantly been conceptualised through the relatively crude notion of 
'global pipelines' (Bathelt et al., 2004) which risks diminishing the potential quality and importance of such networks vis-à-vis local connections (see recently Berg, 2018; Byrne et al., 2018; Esposito and Rigby, 2018).

A number of scholars have sought to get past the local-distant dichotomy that characterises much cluster theory through examining 'territorial knowledge dynamics'. Crevoisier and Jeannerat (2009) for example highlight that while classic innovation milieu perspectives suggest that milieu are open to external knowledge, the concept of multilocation milieu might better reflect the current possibilities for interactions and the rich learning that take place at distance. More attention should be paid, they argue, to exploring "multi-location milieus, which articulate rich proximity learning with intense interaction at medium and long distance" $(2009 ; 1234-1235)$. The authors propose the concept of anchoring of knowledge to bring literature on territorial economies closer to that on transnationalism and mobility, whereby anchoring is the way in which mobile knowledge interacts, or does not interact, with its new context. Rather than simply local 'buzz' enhanced by geographical proximity, local anchoring relates to the local capacity to create strategic connections between different networks (Crespo and Vicente, 2016). As such, Crevoisier and Jeannerat (2009) argue that "it is not a question of losing sight of the role played by local milieus in economic change but more one of understanding how and why some of these milieus succeed in using the new possibilities that open up to them" $(2009 ; 1234)$.

The recent work of Rekers (2016) has usefully sought to shift the discussion from processes of knowledge creation in symbolic knowledge industries, to processes of knowledge diffusion. This process, she argues, is one that like knowledge creation is highly social; however, due to way in which cultural products are received in an act of 
interpretation, it is also one that involves intermediary organisations that contribute to a product's legitimacy. With particular regard to cultural products, Rekers argues that these need to be validated by "intermediaries localized in particular nodes of excellence" (2016; 1059), and also importantly that the evaluation of the value of a particular cultural product, and the value of the symbolic knowledge associated with this, depends on one's reference framework and perspective, which varies across space. Intermediaries in nodes of excellence thus become key to in preparing marketplaces in other cities.

\section{Methodology}

The discussion presented in this paper is based upon qualitative semi-structured interviews with 26 individuals, over 22 interviews, who work within the music economy in north west England. As the key concern of this research was with the socio-spatial networking strategies of those working in the north west music economy, a qualitative approach was adopted as it affords greater importance to the agency and economic and social practices of the research participants (Watson and Beaverstock, 2014) in creating networks between locales. Interviews were undertaken between June 2015 and July 2016. Interviewees were predominantly record label managers, but also included a range of other actors including individuals involved in PR, journalism, music publishing, live music promotion and studio engineering (see Table 1). Those interviewees working for record labels came predominantly from three main genres - Indie, Punk and Dance - while many interviewees, such as those working in PR and publishing, worked across a wide range of genres. 
Table 1: Profiles of interviewees

\begin{tabular}{|c|c|c|}
\hline $\begin{array}{l}\text { Interview } \\
\text { Number }\end{array}$ & Employment details & Location \\
\hline 1 & Label manager, independent record label & Manchester \\
\hline 2 & Music journalist & Manchester \\
\hline 3 & Label manager, major-affiliated record label & Liverpool \\
\hline 4 & Recording studio engineer & Liverpool \\
\hline 5 & Manager, PR company & Rochdale \\
\hline 6 & $\begin{array}{l}\text { Two participants: label manager and assistant manager, } \\
\text { independent record label }\end{array}$ & Manchester \\
\hline 7 & Label manager, independent record label & Manchester \\
\hline 8 & Label manager, independent record label & Liverpool \\
\hline 9 & Live music promoter & Manchester \\
\hline 10 & Label co-manager, DIY record label & Manchester \\
\hline 11 & Artists and repertoire, major-affiliated record label & Liverpool \\
\hline 12 & Label manager, independent record label & Manchester \\
\hline 13 & Label manager, independent record label & Manchester \\
\hline 14 & Punk fanzine producer & Manchester \\
\hline 15 & Two participants: label co-managers, DIY record label & Manchester \\
\hline 16 & Recording studio engineer & Cheshire \\
\hline 17 & Label co-manager, independent record label & Manchester \\
\hline 18 & Label manager, DIY record label & Liverpool \\
\hline 19 & Recording studio engineer & Manchester \\
\hline 20 & Label manager, independent record label & Manchester \\
\hline
\end{tabular}




\begin{tabular}{|l|l|l|}
\hline 21 & Label manager, independent record label & Manchester \\
\hline 22 & Head of rights management, independent music publisher & Liverpool \\
\hline 23 & Two participants: label co-managers, DIY record label & Manchester \\
\hline
\end{tabular}

Interviews lasted between 30 minutes and 90 minutes. Questions centred on the nature of the activities undertaken by the participants; the nature and dynamics of the music economy in the region; important social and professional networks made and maintained beyond the region; and the level and nature of any engagement with music industry companies in London. Questions were adapted as necessary depending on which area of the music economy the participants were from. All interviews were recorded and transcribed, and transcripts were subsequently analysed using systematic coding and recoding based around key themes and common categories emerging from the data, considered in relation to the overall theoretical framework. Quotes, identified by interviewee number only to remain the anonymity of participants, are used in the discussion to emphasise key points of concern, rather than presented as being representative of all views. Supporting the qualitative research, a GIS mapping exercise was also undertaken in order to provide an understanding of the spatial distribution of music economy companies and infrastructure across the region. Locational data were obtained from the publication Music Week, which produces an annual directory for the UK music industry.

\section{The music economy of the north west: 'healthy scenes' but not an industry}

A key finding from research interviews was that very few of the interviewees considered themselves to be part of a formal music 'industry' as one might consider present in a major global music production centre like London. Rather, interviewees emphasised the sociality of 
working in music in the north west and contrasted it with the focus on the 'business' of music that characterises larger centres. A manager of a major-affiliated record label in Liverpool for example noted that "there isn't really an industry within Liverpool... everyone knows everyone but it's not really an industry when it comes to producing records and putting them out there" (Interview 3). The interviewee went on to note that music in the region is "more of a healthy scene where everyone knows what's going on or interacts quite healthily". Here, a music scene is understood as a geographic location that brings together musical and business talent - including artists, producers, engineers, industry executives, audiences - across social networks and physical space - neighbourhoods, recording studios, bars, clubs, and live music venues (Bennett and Peterson, 2004; Florida and Jackson, 2010). Taken together, these social networks and physical spaces of musical creativity in the city are crucial to maintaining music scenes (Watson et al., 2009). Reflecting this, the same interviewee went on to note that “it doesn't really feel like there's an industry here which is a shame really because it's got all the things it needs for an industry". This quote is suggestive of the presence of a supporting infrastructure for local scenes. Such a statement is supported by the results of the GIS mapping (Figure 1) which displays music economy infrastructure present across the region, including record labels, live music venues, recording studios, artist management, booking agents and music publishers, as well as supporting activities provided by companies outside the music industry such as media, design and digital. While activities are located across the region, the significant concentration of music infrastructure within the two main cities of Manchester and Liverpool is clearly shown. 
Figure 2: Mapping of key music economy activities in north west England



Created using ESRI Arcmap 10.6. Contains OS data @ Crown Copyright and database right 2018. 
If one compares these concentrations to those of music companies in London (see Watson, 2008), they are significantly smaller than those in the UK's 'global music city'. Yet, relative size aside, taken at face-value the tight urban concentrations of music industry companies and supporting infrastructure shown would support assertions in the literature regarding the tendency for the music industry to form clusters in cities. These clusters are considered to support localised interactions (Watson et al; 2009; Tironi, 2012; Hracs 2015), and act as the locales from artists can draw inspiration and as such where musical innovation is fostered (Klement and Strambach, 2019a). Further, the presence of a significant number of live music venues, considered to be central to the maintenance and performance of local music scenes (Ballico and Carter, 2018), would suggest the presence of vibrant local music scenes. All of this would seemingly provide evidence to support the continued underpinning of regional creative economies by policies which focus on the development of creative urban clusters.

Yet as Brennan-Horley and Gibson (2009) emphasise, while this type of mapping of firm locations and densities is informative at the general level, it tells use little about the everyday spatial, social and economic relationships that may or may not exist between creative practitioners within particular cities or regions. While the lack of formal industry connections across the region was highlighted in interviews, so too was the friendly, supportive and collaborative nature of local music scenes. The manager of an independent record label in Manchester, for example, described the city as "big enough for stuff to happen, but small enough to have a neighbourhood feel to it as well" (Interview 13). It was evident from interview responses that the local music economy is highly informal and based around a series of more-or-less strongly connected social networks and communities of practice. While an ethic of collectivism is noted as a central defining feature of identity for 
DIY independent practitioners in particular (Strachan, 2007), such an ethic appears to permeate the north west music economy more broadly. The manager of PR company based in Rochdale, for example, described how "Everyone knows everybody else, which is a good thing because you tend to find people help each other out. It doesn't seem to be like a competition... they look after each other in Manchester" (Interview 5). The same supportive attitudes were evidenced as occurring in Liverpool, with the manager of a major-affiliated label in Liverpool describing how "we've got time for everyone who's up and coming... because obviously we know how the industry works, we just try and help everyone out when they need it really" (Interview 3). Yet, there was also reflection from interviewees on the extent to which scenes are often insular. It was evident that while strong social connections may exist within scenes, they usually do not exist across different scenes. The co-manager of an independent label in Manchester noted that "the scene here is very incestuous and everything is on top of each other, you're not necessarily going to see everything" (Interview 17). A recording studio engineer based in Manchester noted that "it just feels so scattered... there are pockets of people everywhere, but they've all got their heads down and just getting on with what they do (Interview 19). This insularity within, and disconnections between, various scenes would appear to lie at the heart of the feeling that there is no singular music 'industry' that ties musical activity together.

The issue of insularity extends to relations across the two major regional cities of Manchester and Liverpool. While Witts $(2018 ; 26)$ draws on case studies of particular artists and entrepreneurs to suggest that the two cities have "a dynamic and mutual relationship" with regards to the production, performance, reception and circulation of music, the findings from my own research suggest a more complicated pattern of connections and disconnections. On one hand, a live music promoter in Manchester noted that "In terms of 
connections, no not really... no more established networks; they don't really exist between the two cities" (Interview 9), while the manager of a major-affiliated label based in Liverpool noted that "There are only personal interactions between the base cities. It's not an industry interaction. There's nothing drawing us to Manchester other than if we see someone that we want to sign coming there or one of our acts is playing live there" (Interview 3 ). On the other hand, two interviewees involved in live music promotion, one in Manchester and one in Liverpool, described how local booking agents across the region will share information with each other when booking shows, such that they are not in direct competition. By cooperating in this manner, live promoters can ensure that each live show has a sufficient audience to be profitable. With live music scenes in the north west being identified by research participants not only as some of the most vibrant in the country, but also crucial to the way in which social relationships are built with local scenes, there was a clear sense that collective actions in promoting a vibrant local music economy were to the benefit of everyone involved.

\section{The importance of connections beyond the region}

While understanding the spatiality and quality of the social relationships that occur within and across the region gives an important sense of the ways in which localised creative scenes function, one cannot consider the region only in geographically bounded terms. Activities crucial to these scenes can be often be based well outside their home region (Chapain and Comunian, 2010). Klement and Strambach (2019b), for example, find in their recent analysis of the emergence of new music genres that while new genres spawn mainly from localised knowledge sources, symbolic knowledge creation rarely happens without contributions of extra-local knowledge. It was evident through the interviews that the same dynamics of informality that define local scenes also define social and business relationships developed beyond the region. This suggests that the local cultural economy has a transient 
and fluid spatial dimension as well as a more static, territorially-focused dimension. For most individuals and companies, social and business relations stretched beyond the region, albeit to varying degrees. One of the most-cited connections in this regard was with Leeds, with one interviewee in Liverpool describing the north west 'regional' music scene as consisting of "two big cities, two big powerhouses [Manchester and Liverpool] and Leeds as well" (Interview 11), while another from Manchester noted that "loads of people from Manchester and Liverpool travel to Leeds, it's a massive connection" (Interview 15). Further, there was a sense of a broader 'northern' music scene existing, with an A\&R manager from Liverpool noting that one advantage of being based in the city was that they had "one foot on the northern scene, there's records that are developing out of Liverpool, up north, Leeds, Newcastle, Sheffield, Manchester" (Interview 11). Indeed, this 'northern scene' can be considered to stretch even further, with a number of interviewees noting significant connections with Scotland, with geographical proximity (relative compared to London-based companies) being noted as an advantage in this regard. The same interviewee noted for example that "Over the last couple of years we've worked a lot of Scottish acts... I can be in Glasgow at the same speed that I can be in London, so we're better placed to sign Scottish acts than maybe a London label is" (Interview 11).

For many of the interviewees, important social and economic connections stretched well beyond the UK, with the US and Europe being particularly significant in this regard. One interviewee noted that "We are as established in France as we are in the UK as a label... we might have even sold more records in France than we have England... We kind of think about the bigger picture, about Europe as a whole rather than the UK" (Interview 15). Another interviewee running a small label in Manchester estimated that seventy percent of the output of the label went straight to the United States (Interview 7), while an interviewee 
from another Manchester label described the importance of a fan base for the label in the United States who "have never been to any of our events or seen any of our bands live at all, because they've just never got across the Atlantic, but who are just totally in love with the whole roster" (Interview 17).

Similar music scenes in different places are often connected through the exchange of recordings, band and fans (Bennett and Peterson, 2004), and while these relations may remain intangible and affective, they may in some cases become more concrete. For some of the labels, international connections that were made initially through personal social networks of shared musical taste became consolidated through formal business relationships. A label manager in Manchester noted for example that the label managed the European distribution and PR for a number of American labels, where a relationship had developed because the labels considered themselves as releasing music of a similar aesthetic only within different territories. In this way, a shared musical taste or knowledge is shown to be important in the formation and maintenance of inter-local social and economic systems in the music economy (Kruse, 2010).

One of the most significant mechanisms through which extra-regional connections are made in the music economy is through touring. As the manager of a DIY record label based in Liverpool noted, 'it's just like a spider's web in that every time the band goes to a place, they make a connection and bring it back" (Interview 18). In this way, the benefits of touring go beyond the income generated from shows. For artists and bands, it can foster new social connections that may result in further opportunities to play shows. One interviewee, who as well as running a label was in an actively touring band, noted that "being a touring band ourselves, we've made a lot of contacts; we've got friends all over Europe. Yeah, I've been 
to like as far as Latvia, Lithuania, Poland and made contacts" (Interview 10). For labels, having actively touring bands on the roster, and being present at gigs, helps both with marketing and in making new business connections, formal or informal, with companies outside of the home city, region or country. The same interviewee described how labels often organise gigs together, putting each other's bands on across their respective territories, and doing the same with releases. This can be particularly important when an artists and/or label is looking to 'break-through' in a new territory; one interviewee noted that "once you get to the touring, that's the key step then to break through into mainland Europe, a new audience" (Interview 18). These findings echo those of Kruse (2010) who also emphasises the role of touring in making interlocal connections and the numerous ways in which the economic structures of indie music are interrelated with social practices. As Kruse notes, the development of 'over-lapping' trans-local networks evidences the ways in which the economic structures of music are interrelated with social practices, bringing people and institutions in disparate local scenes together into broader systems of cultural production.

\section{"The best thing to do with London is just ignore it": disconnection and othering}

Arguably the most crucial set of trans-local networks available to those working in the music economy in the north west is with the main hub of the UK music industry in London. These include links with the production and distribution networks of the major corporations, and other key music industry 'intermediaries' such as radio and the music press. As Halfacree and Kitchen (1996) note in their account of Manchester's commercial music success in the 1990s, active local press and radio stations can play an important role in cultivating local following. However, press and radio stations with national and international reach tend to be almost exclusively located in London. As Strachan (2007) notes in his examination of the activities of micro-labels, their production of recordings is consistently hindered by an unstable 
relationship with such crucial 'bridging institutions', or what otherwise be termed key music industry 'intermediaries', which leads to a large degree of economic uncertainty. The instability of this relationship has a number of facets, including the size and capacity of the label both in terms of human and financial resources, which may limit the ability of these labels to develop the social and/or professional networks required to link to these bridging institutions.

However, it was also clear that geography and territory play a significant role in this regard. While the north west has such intermediaries, these tend to be limited to local and regional in terms of reach. Those intermediaries with national and international reach remain almost exclusively located in London, with artists from the region often relocating to London to reach national and global markets (Mazierska, 2018). As a recording studio engineer based in Liverpool noted, “I don't think anybody up here is able to go onto super stardom without eventually having to go through the London music industry and through the labels and through the radio pluggers and so on, who are all based in London" (Interview 4). It is notable then, with regards to the potential growth of a regional music economy in economic terms, that a narrative of disconnection from the music 'industry' in London came through strongly across the interviews. Only two of the record labels interviewed had formal relationships with the larger corporations of the industry, and only one more was identified outside the interview sample. The manager of one these labels, based in Liverpool, noted that "when it comes to ones that operate in a mainstream level, I think we're probably one of the few. I can't really think of anyone else as far North as us who operate in the mainstream thing" (Interview 3). 
Interviewees were keenly aware of the hegemony of London as the main hub of the music industry in the UK. Many of the interviewees explicitly positioned their own work, the social infrastructure, and musical creativity in the city or region more broadly, against the music 'industry' of London. This is reflective of the tendency identified by Strachan (2007) among small-scale practitioners in music to base their shared identities in relation to an 'othered' music industry. Attitudes towards this othered industry in London ranged from reluctant engagement: “you've just got to embrace it I guess" (Interview 11); to ambivalence: "the best thing to do with London is ignore it" (Interview 17); to a stance of resistance to London's cultural hegemony: "I think there's a defiance about Manchester where it's a case of kicking against London. We've done it before, you know? We don't need London" (Interview 2). For the limited number of companies engaged with the major corporations, or otherwise more integrated into the industry, attitudes were understandably generally more positive and pragmatic. The situation between the north-west and London might then be categorised as the type of love-hate relationship that has been more broadly identified across the UK's regional creative economies (see for example Chapain and Comunian, 2010, on Birmingham and Newcastle-Gateshead), with most interviewees recognising the need to engage with the corporate industry in London to at least some degree in order to reach larger audiences. An A\&R manager from Liverpool, for example noted that "We are in a joint venture with [major corporation] ... we do need to have some kind of involvement in London, because a lot of the major players are down there. (Interview 11). However, the above situation of a formal relationship is very much an outlier, and there was a clear sense amongst most of the small labels that where individuals or companies did seek to make connections in to the music industry in London, this often proved to be very difficult. The owner of an independent label in Manchester spoke about some of the difficulties in breaking a band into the London live music scene because of the issue of connecting with the right 
booking agents in London. He considered that this lack of connections into London might be having a significant impact on the ability of the band to achieve commercial success:

What we've never been able to do with the [band name] is get them a booking agent... [name omitted - a leading producer] is based in London and his opinion is where they went wrong is they moved to Manchester and they should have moved to London because all the agents are in London, all the booking agents they're out scouring, all the traditional press and all your publishers, they're all in London." (Interview 1)

Such a sentiment was echoed by the manager of an independent label based in Manchester who noted that, in terms of live shows in London, "Publishers are going to be there. There are almost certainly major labels going to be there. You know those sorts of shows only happen in London. London is pivotal..." (Interview 12).

The dominance of London, and the concentration of music infrastructure and services contained therein, is of course a long-standing feature of the music industry in the UK. Weinstein (2014) for example, in her examination of Heavy Metal in the regional UK city of Birmingham, describes not only the dominance of London in the 1960s and 1970s, but also the ways in which music professionals and journalists 'looked down' upon regional music scenes and bands. This echoes the type of disinterest and disconnection felt by those working in the contemporary music economy in the north west. The assistant manager of an independent record label based in Manchester, reflected that music industry companies and intermediaries in other countries "see Manchester as kind of more significant than we do in this country" (Interview 6). However, evidence suggests that this has been exacerbated in 
recent times by the emergence of online $A \& R$ and the withdrawal of major labels from the UK regions. The head of rights management at an independent music publisher based in Liverpool reflected on the 'retreat' of major labels from the north west, describing how "A regional team would be working indefinitely in Manchester just to make sure that they saw every new band that was going on. It has changed since then... I am talking back to the early noughties" (Interview 22). He went on to note that it was "a different kind of time then, a lot of money then flying around record labels... It also made sense to have a company up in the north west". Another interviewee noted that "I think the Northern acts slip under the radar of the Southern labels.... they are stuck in London, you know? They don't ever move from there" (Interview 12).

The sense of the relationship between the music industry in London and those working in music in the north west, then, was that it is hierarchical and very much one-way, with those based in the north west having to be pro-active with networking and travelling in order to engage with companies, intermediaries and venues in London, with these visits not being reciprocated. In her account of the music economy in Perth, Australia, Ballico (2017) notes how the geographic isolation of the city poses challenges for local musicians and extended a 'creative distance' between the city and the rest of the country. While one would not consider either Manchester or Liverpool as being geographically isolated from London in relative terms, and unlike Perth both are key locations on national and international touring circuits, there is nevertheless a perception that they are becoming increasingly isolated from London. This presents challenges to both artists and labels looking to engage with the major corporations of the mainstream music industry. Yet, as the increasing isolation of the London music industry demonstrates a detachment of London from the UK's regions, so too actors in the regional economy are adopting socio-spatial strategies that avoid and bypass London. For 
example, when reflecting on this matter, one interviewee noted that "I increasingly get a sense having spoken to people that, most people just stay out of that [London] thing. A lot of labels seem to have links to North America more than they do London ... (Interview 13).

\section{Conclusions}

While the region has been one of the key spatial units at which creative industries policy in the UK has been formulated, in this paper I have argued that the notion of 'regional' creative economic policy is rendered problematic because it is reliant on an evidential base that fails to elaborate how the creative industries operate in reality, and as such is unable to account for the geographical and social complexities of connections and disconnections that characterise and shape contemporary regional creative economies. Through a detailed examination of the music economy of north west England, this paper has begun the task of addressing this significant empirical deficit. The research finds evidence of vibrant local music scenes, supported by a well-developed music infrastructure, marked by informality, sociality and supportiveness, chiming with perspectives emphasising dense local networks and the centrality of symbolic knowledge to these industries (Martin and Moodysson, 2011). Yet, it is also noted that scenes can be highly insular, and for most participants the connections within the regional music economy were neither well developed nor formalised enough for it to be considered an 'industry'. At a regional level, there was evidence of informal social relations existing between the two main cities of Liverpool and Manchester, and a sense that the development and vibrancy of the musical economies in the two cities is to some extent intertwined, yet they were also were marked as having very different scenes, with few formal connections existing between the two cities. Rather, the firms and individuals interviewed were more generally more active in building formal networks outside the region than inside it, across a 'multi-location milieu' (Crevoisier and Jeannerat, 2009) both within what might 
be considered a broader 'northern' music economy stretching as far as Scotland and, perhaps more importantly, with continental Europe and the USA. Of course, this is to describe a rather generalising pattern, and the relative importance of local fixity vis-à-vis intra-regional, inter-regional and international networks differed for different individuals and different firms, based upon a variety of entrepreneurial-strategic and social-aesthetic motivations.

However, the most significant finding to emerge from the analysis relates to the perceived insularity of London as the key centre for national and international intermediaries, and the related disconnection with London of music companies in the north west. As Oakley $(2004 ; 75)$ notes, while "the ecology of creative industries firms at the local level is often an instance of organic bottom-up development, resulting in a confusing, but essentially thriving system" at the national level "it is a case of a few dominant media companies". The music industry is arguably characterised by such an oligopoly more than any other industry. Following the work of Rekers (2016) on innovation diffusion, in this paper I have argued that London as the UK's 'global music city' (Watson, 2008), is the key centre of validation of symbolic knowledge in this industry. While national cultural industries policy has emphasised the development of the cultural economy in the regions, as Rekers notes, the assumption cannot be made that symbolic products will readily diffuse and be exported widely "in the absence of strong links to validating intermediaries in other, more prestigious cities" (2016; 1072). Thus, as Rekers argues, addressing policy challenges around the creative industries requires "a better appreciation of the role of local factors in how innovations get validated and why this varies across industries and geographic contexts" (2016; 1060). Given both London's central role in validating musical innovation, and the gatekeeping role played by London companies in terms of access to wider national and international markets, the insularity of London and associated disconnection with the north 
west region presents significant and very tangible challenges to the health and vibrancy of the local music economy.

If one considers these findings of this paper in the context of 'local anchoring' (Crevoisier and Jeannerat, 2009; Crevoisier, 2016) - as it relates to the local capacity to create strategic connection between different networks (Crespo and Vincente, 2016) - then one might argue that "policy should primarily identify the 'missing links' between networks and provide 'surgical' support to create them rather than providing generic support to specific industries" (Jeannerat and Crevoisier, 2016; 187). Currently, the dominance of London's music industry cluster within the UK places many London-based companies and intermediaries in a position where they do not need to engage with companies elsewhere in the UK. At the same time many regional companies struggle to gain access to key gatekeepers and intermediaries (e.g. labels, music publishing, PR, booking agents) in London, which are not only embedded within the London industry, but also have national and global reach. Therefore, with regards to creative economy policy, what would seem to be required in this instance are clearly defined regional policies that focus on developing improved relationships between regional companies and London companies, clients, and supply chains, where markets are national or global. As such, the findings regarding disconnection between companies in the North West and London are set within the broader framework of concerns regarding the spatial rebalancing of the UK economy.

As previously noted, the Creative Industries Sector Deal of the UK Government's Industrial Strategy states that the UK is to develop "more world-class creative industries clusters to narrow the gap between London, the South East and other regions" (HM Government, 2018; 14). Yet, as Varró and Lagendijk (2013) argue, regional policy can only 
diminish spatial inequalities effectively if it is addressing the relations through which these inequalities are produced. Two key issues emerge from this paper in this regard. First, as Oakley (2006) argues, there is the need to break up the notion of the creative industries as a homogenous group. As a case in point, given the level of oligopoly in the music industry, and the concentration of the music industry in London, any policy that seeks to better connect the regional creative economies with London would arguably act to strengthen London's position vis-à-vis the regions. Second, while the conventional logic might be that the creative and media must go through London as an obligatory point of symbolic validation and passage point to wider markets, this is clearly only partially true. Given the dynamic and diverse social-spatial relations identified in this paper, developed by 'disconnected' actors in the north west music economy as a strategy to cope with their disconnected status, cluster-based and London-centric national creative industries policy could potentially be limiting to the music economies of the UK regions. Rather, the findings suggest a promising alternative creative economy policy that promotes extra-regional networking, one in which creative industry professionals are supported in developing multi-scalar links with actors and companies across the UK regions or internationally. Such a strategy towards policy may seem counterintuitive when viewed from the perspective of national policy making, but when considered as part of a broader frame can be seen as part of an alternative and more inclusive creative economy policy that seeks to develop 'multi-locational milieus' (Crevoisier and Jeannerat, 2009) of regional cities, which articulate the rich proximity learning of informal an formal creative economies with rich and meaningful interactions across a number of geographical scales. 


\section{Acknowledgements}

I am very grateful to John Harrison, Ben Derudder and three anonymous referees for their constructive feedback on earlier versions of this paper, and to Mark Szegner for his assistance with the mapping element of the paper. I would also like to thank Aaron Thurstance, Caroline Stone and Christopher Teece for their assistance with various elements of data collection and analysis as part of student research assistantships. The research reported in this paper was made possible by a Royal Geographical Society small grant awarded in 2015, and my sincere thanks go to the Society for their support for this project.

\section{References}

Ballico, C. (2016). Another typical day in this typical town: Place as inspiration for music creation and creative expression. Australian Geographer 48(3), 349363.

Ballico, C. and Carter, D. (2018) A state of constant prodding: live music, precarity and regulation. Cultural Trends, 27(3), 203-217

Bathelt, H., Malmberg, A. and Maskell, P. (2004). Clusters and knowledge: local buzz, global pipelines and the process of knowledge creation. Progress in Human Geography, 28, $31-56$.

Bennett, A. and Peterson, R. (2004). (Eds.). Music scenes: local, translocal, and virtual. Nashville, TN: Vanderbilt University Press.

Berg, S. (2018). Local buzz, global pipelines and Hallyu: The case of the film and TV industry in South Korea. Journal of Entrepreneurship and Innovation in Emerging Economies, 4(1), 33-52.

Brennan-Horley, C. \& Gibson, C. (2009). Where is creativity in the city? Integrating qualitative and GIS methods. Environment and Planning A 41, 2595-2614. 
Byrne, E., Hobbs, J. and Doran, J. (2018) Visualization of firm linkages in the Chicago ICT cluster. Regional Studies, Regional Science, 5(1), 94-97.

Chapain, C., Clifton, N. \& Comunian, R. (2013) Understanding creative regions: Bridging the gap between global discourses and regional and national contexts. Regional Studies 47(2), 131-134.

Chapain, C. \& Comunian, R. (2010) Enabling and inhibiting the creative economy: The role of the local and regional dimensions in England. Regional Studies 44(6), 717-734.

Christophers, B. (2008). The BBC, the Creative Class, and Neoliberal Urbanism in the North of England. Environment and Planning A: Economy and Space 40(10), 2313-2329.

Crespo, J. and Vicente, J. (2016) Proximity and distance in knowledge relationships: From micro to structural considerations based on territorial knowledge dynamics (TKDs). Regional Studies 50(2), 202-219.

Crevoisier, O. (2016) The economic value of knowledge: Embodied in goods or embedded in cultures? Regional Studies, 50(2), 189-201.

Crevoisier, O. and Jeannerat, H. (2009). Territorial knowledge dynamics: From the proximity paradigm to multi-location milieus. European Planning Studies, 17(8), 1223-1241.

Cunningham, S. D. and Higgs, P. L. (2008) Creative industries mapping: where have we come from and where are we going? Creative Industries Journal, 1(1). pp. 7-30.

Department for Culture Media and Sport (DCMS) (2000) Creative Industries - The Regional Dimension. DCMS, London.

Department for Culture Media and Sport (DCMS) (2001) Creative Industries Mapping Document 1998. DCMS, London.

Esposito, C. R. and Rigby, D. L. (2018). Buzz and pipelines: the costs and benefits of local and nonlocal interaction. Journal of Economic Geography https://doi.org/10.1093/jeg/lby039 
Florida, R., \& Jackson, S. (2010). Sonic City: The Evolving Economic Geography of the Music Industry. Journal of Planning Education and Research, 29(3), 310-321.

Florida, R., Adler, P. and Mellander, C. (2017). The city as innovation machine. Regional Studies 51(1), 88-96.

Granger, R. \& Hamilton, C. (2010) Re-spatializing the creative industries: a relational examination of underground scenes, and professional and organizational lock-in. Creative Industries Journal 3(1), 47-60.

Halfacree, K.H., and Kitchin, R.M. (1996). 'Madchester rave on': placing the fragments of popular music. Area 28(1), 47-55.

Haughton, G., Deas, I., Hincks, S., and Ward, K. (2016) Mythic Manchester: Devo Manc, the Northern Powerhouse and rebalancing the English economy. Cambridge Journal of Regions, Economy and Society, 9(2), 355-370.

HM Government (2018) Industrial Strategy: Creative Industries Sector Deal. Available from: https://www.gov.uk/government/publications/creative-industries-sector-deal (accessed 20/02/2019)

Hracs, B. J. (2015). Cultural intermediaries in the digital age: The case of independent musicians and managers in Toronto. Regional Studies, 49(3), 461-475.

Jayne, M. (2005). Creative industries: the regional dimension? Environment and Planning C: Government and Policy 23, 537-556.

Jeannerat, H. and Crevoisier, O. (2016) Editorial: From 'territorial innovation models' to 'territorial knowledge dynamics': On the learning value of a new concept in regional studies. Regional Studies, 50(2), 185-188

Klement, B. and Strambach, S. (2019a). Innovation in creative industries: Does (related) variety matter for the creativity of urban music scenes? Economic Geography DOI: $10.1080 / 00130095.2018 .1549944$ 
Klement, B. and Strambach, S. (2019b). How do new music genres emerge? Diversification processes in symbolic knowledge bases. Regional Studies DOI: $10.1080 / 00343404.2019 .1580817$

Kruse, H. (2010). Local identity and independent music scenes, online and off. Popular Music and Society 33 (5), 625-639.

Lee, N. (2017). Powerhouse of cards? Understanding the 'Northern Powerhouse'. Regional Studies, 51(3), 478-489.

Markusen, A. (2010). Organizational complexity in the regional cultural economy. Regional Studies, 44(7), 813-828.

Martin, R. and Moodysson, J. (2011). Innovation in symbolic industries: The geography and organization of knowledge sourcing. Regional Studies, 19(7), 1183-1203.

Martin, R. (2015). Rebalancing the spatial economy: The challenge for regional theory. Territory, Politics, Government, 3(3), 235-272.

Martin, R., Pike, A., Tyler, P. and Gardiner, B. (2016). Spatially rebalancing the UK economy: Towards a new policy model? Regional Studies, 50(2), 342-357.

Mazierska, E. (2018). Introduction: Is it really grim up north? Popular music in the north of England. In E Mazierska (ed.) Sounds Northern: Popular Music, Culture and Place in England's North. Sheffield: Equinox, pp. 1-14.

Noonan, C. (2012). The BBC and decentralisation: the pilgrimage to Manchester. International Journal of Cultural Policy, 18(4), 363-377.

Oakley, K. (2004). Not so cool Britannia: The role of the creative industries in economic development. International Journal of Cultural Studies 7(1), 67-77.

Oakley, K. (2006). Include us out - economic development and social policy in the creative industries. Cultural Trends, 15(4), 255-273. 
Parr, J. B. (2017). The Northern Powerhouse: a commentary. Regional Studies, 51(3), 490500.

Porter, M. E. (1998). Clusters and the new economics of competition. Harvard Business Review 76 (November-December), 77-90.

Pratt, A. C. (2005) Cultural industries and public policy: An oxymoron? International Journal of Cultural Policy 11(1), 31-44.

Pratt, A. C. (2009) Policy transfer and the field of cultural and creative industries: What can be learned from Europe?, in: L. Kong \& J. O’Connor (Eds) Creative Economies, Creative Cities: Asian-European Perspectives, pp. 9-24 (Dordrecht: Springer Press).

Pratt, A. C. (2010). Creative cities: Tensions within and between social, cultural and economic development, City, Culture and Society, 1(1), 13-20.

Rekers, J.V. (2016). What triggers innovation diffusion? Intermediary organizations and geography in cultural and science-based industries. Environment and Planning C: Government and Policy, 34(6), 1058-1075

Strachan, R. (2007). Micro-independent record labels in the UK: Discourse, DIY cultural production and the music industry. European Journal of Cultural Studies 10(2), 245-265.

Storper, M. and Venables, A. J. (2004) Buzz: face-to-face contact and the urban economy. Journal of Economic Geography 4 351-70

Taylor, C. (2006) Beyond advocacy: Developing an evidence base for regional creative industries strategies, Cultural Trends 15(1), 3-18.

Tironi, M. (2012) Enacting music scenes: Mobility, locality and cultural production. Mobilities 7(2), 185-210. 
Trippl, M., Grillitsch, M., Isaksen, A. and Sinozic, T. (2015). Perspectives on cluster evolution: Critical review and future research issues. European Planning Studies, 23(10), 2028-2044.

van Heur, B. (2010). Small cities and the geographical bias of creative industries research and policy. Journal of Policy Research in Tourism, Leisure and Events, 2(2), 189-192.

Varró, K. and Lagendijk, A. (2013). Conceptualizing the region - in what sense relational? Regional Studies, 47(1), 18-28.

Watson, A. (2008) Global music city: Knowledge and geographical proximity in London's recorded music industry. Area, 40(1), pp. 12-23.

Watson, A. and Beaverstock, J. V. (2014) World city network research at a theoretical impasse: on the need to re-establish qualitative approaches to understanding agency in World City Networks. Tijdschrift voor Economische en Sociale Geografie 104(1), 90108.

Watson, A., Hoyler M. and Mager, C. (2009) Spaces and networks of musical creativity in the city. Geography Compass, 3 856-878.

Watson, A. and Taylor, C. (2014) Invisible agents and hidden protagonists: Rethinking creative cities policy. European Planning Studies, 22(12), 2429-2435.

Weinstein, D. (2014) Birmingham's Postindustrial Metal. In Brett Lashua, Karl Spracklen and Stephen Wagg (eds.) Sounds and the City. Basingstoke: Palgrave Macmillan, pp. $38-54$.

Witts, R. (2018) Manpool, the musical: harmony and counterpoint on the Lancashire plain. In Ewa Mazierska (ed.) Sounds Northern: Popular Music, Culture and Place in England's North. Sheffield: Equinox, pp. 17-36. 